\title{
Fetal cell microchimerism: a protective role in autoimmune thyroid diseases
}

\author{
Valentina Cirello ${ }^{1,2}$, Roberta Rizzo ${ }^{3}$, Milena Crippa ${ }^{4}$, Irene Campi ${ }^{1}$, Daria Bortolotti ${ }^{3}$, \\ Silvia Bolzani ${ }^{3}$, Carla Colombo ${ }^{1,5}$, Guia Vannucchi ${ }^{1}$, Maria Antonia Maffini ${ }^{5}$, \\ Federica de Liso6 ${ }^{6}$, Stefano Ferrero ${ }^{7,8}$, Palma Finelli ${ }^{4,9}$ and Laura Fugazzola ${ }^{1,2}$ \\ ${ }^{1}$ Endocrine Unit, Fondazione IRCCS Ca' Granda, Via F. Sforza, 35-20122 Milan, Italy, ²Department of \\ Pathophysiology and Transplantation, University of Milan, Milan, Italy, ${ }^{3}$ Section of Microbiology and \\ Medical Genetics, Department of Medical Sciences, University of Ferrara, Ferrara, Italy, ${ }^{4}$ Laboratory of Medical \\ Cytogenetics and Molecular Genetics, Istituto Auxologico Italiano, Milan, Italy, ${ }^{5}$ Department of Clinical Sciences \\ and Community Health, University of Milan, Milan, Italy, ${ }^{6}$ Laboratory of Clinical Chemistry and Microbiology, \\ Fondazione IRCCS Ca' Granda, Milan, Italy, ${ }^{7}$ Division of Pathology, Fondazione IRCCS Ca' Granda, Milan, Italy, \\ Departments of ${ }^{8}$ Biomedical, Surgical and Dental Sciences and ${ }^{9}$ Medical Biotechnology and Translational Medicine, \\ University of Milan, Milan, Italy
}

Correspondence should be addressed to L Fugazzola

Email

laura.fugazzola@unimi.it

\section{Abstract}

Objective: The physiological persistence of fetal cells in the circulation and tissue of a previously pregnant woman is called fetal cell microchimerism (FCM). It has been hypothesized to play a role in systemic autoimmune disease; however, only limited data are available regarding its role in autoimmune thyroid disease (AITD).

Design: Circulating FCM was analyzed in a large series of previously pregnant women with Graves' disease (GD), Hashimoto's thyroiditis (HT), or no disease (healthy controls (HCs)). To exclude the possible bias related to placental factors, the polymorphic pattern of human leukocyte antigen-G (HLA-G) gene, which is known to be involved in the tolerance of fetal cells by the maternal immune system, was investigated.

Methods: FCM was evaluated by PCR in the peripheral blood, and the $\mathrm{Y}$ chromosome was identified by fluorescence in situ hybridization in some GD tissues. HLA-G polymorphism typing was assessed by real-time PCR.

Results: FCM was significantly more frequent in HC (63.6\%) than in GD $(33.3 \%)$ or HT (27.8\%) women $(P=0.0004$ and $P=0.001$ respectively). A quantitative analysis confirmed that circulating male DNA was more abundant in $\mathrm{HC}$ than it was in GD or HT. Microchimeric cells were documented in vessels and in thyroid follicles. In neither GD/HT patients nor HC women was the HLA-G typing different between FCM-positive and FCM-negative cases.

Conclusion: The higher prevalence of FCM in HC as compared to GD and HT patients suggests that it plays a possible protective role in autoimmune thyroid disorders. Placental factors have been excluded as determinants of the differences found. The vascular and tissue localization of microchimeric cells further highlights the ability of those cells to migrate to damaged tissues.

\section{Introduction}

During pregnancy, a bidirectional exchange of cells has been observed between the fetus and the mother, which starts between the 4th and 6th weeks of gestation (1). The passage of cells from the fetus to the mother is called fetal cell microchimerism (FCM), whereas that occurring from the mother to the fetus is named maternal cell microchimerism (MCM). Both fetal and maternal microchimeric cells have been shown to persist in the maternal circulation or tissue for decades and to have progenitorlike properties, because they are able to differentiate into different cell types $(2,3,4)$. The most widely used procedure for evaluating FCM is assessing by PCR the

Published by Bioscientifica Ltd. 
presence of male cells in a woman with a previous male pregnancy. By this and other methods, FCM has been extensively studied in autoimmune diseases, particularly systemic ones, because they are more often observed in females and appear to be modulated by pregnancy $(5,6$, $7,8)$. As far as autoimmune thyroid disease (AITD) is concerned, FCM has been documented in Hashimoto's thyroiditis (HT) and Graves' disease (GD) (9, 10, 11, 12, 13). These diseases occur more frequently in women, with a peak incidence during the fertile age. They appear to be related to pregnancy and often have a spontaneous resolution after delivery and an onset or exacerbation in the postpartum period, although their relation with parity is still controversial $(14,15,16)$. In the few available series, which include a limited number of cases, FCM was found to be represented more at the tissue level in HT and GD as compared to non-AITDs $(4,9,10,11,12,13,17)$. Even at the peripheral level, scanty and discrepant results have been reported. In particular, one study that used a PCR-based technique showed that the number of circulating fetal microchimeric cells did not differ between GD and controls (12), whereas another study that used a fluorescence in situ hybridization (FISH) analysis demonstrated that a higher number of circulating fetal cells were found in GD and HT patients as compared to healthy volunteers (18).

Thus, in the present study, we compared the prevalence of FCM in two large populations of parous women with a previous male pregnancy, one including women affected with GD or HT and the other including healthy controls (HCs). Moreover, in order to investigate if possible differences in the prevalence could be the result of placental factors, we assessed the polymorphic pattern of the human leukocyte antigen-G (HLA-G) gene. Indeed, HLA-G molecules are non-classical HLA class I antigens that are expressed by villous trophoblasts and are involved in the reprogramming of the local maternal immune response because they inhibit the activation of decidual $\mathrm{T}$ and NK cells; they have been proposed to positively influence the outcome of pregnancy $(19,20)$. The HLA-G expression profile can be modulated by genetic polymorphisms, mainly two variants at the $3^{\prime}$ UTR, the $14 \mathrm{bp}$ insertion/deletion (rs1704), and the $+3142 \mathrm{C}>\mathrm{G}$ (rs1063320), which influence mRNA stability and protein production and thereby lead to increased/reduced HLA-G expression and soluble HLA-G protein amounts in body fluids $(21,22,23)$. In particular, the $14 \mathrm{bp}$ deletion in hetero- or homozygosis is associated with a higher HLA-G expression (high secretor profile), whereas both the $14 \mathrm{bp}$ insertion and the $+3142 \mathrm{C}>\mathrm{G}$ polymorphism in exon 8 decrease HLA-G expression (low secretor profile). We speculated that a high secretor HLA-G genetic profile, which allows for a stronger control of maternal immune response, might favor the passage of fetal cells to the mother during pregnancy and result in a higher prevalence of FCM. Thus, the HLA-G profile has been correlated with the microchimeric status in GD, HT, and HC.

\section{Subjects and methods}

\section{Patients}

Peripheral blood was collected from 105 female patients with AITDs treated at our institution. To be enrolled, patients must have had at least one male pregnancy preceding the diagnosis of AITD. In particular, 69 women had GD, with a mean age at enrollment of 53.3 years (range 27-85), and 36 had HT, with a mean age at enrollment of 53.1 years (range 33-88). Graves' orbitopathy (GO) was diagnosed in 58/69 GD and in 4/36 HT patients. Peripheral blood was also collected from 66 HCs with one or more male children without neoplastic or autoimmune diseases (mean age 48 years, range 29-80). Moreover, none of the control women had a thyroid disease, as assessed by $\mathrm{FT}_{4}, \mathrm{TSH}$, anti-thyroglobulin and anti-thyroperoxidase autoantibodies, and neck ultrasound. None of the included subjects had a history of other potential sources of chimerism, such as blood transfusion, organ transplant, twin siblings, or abortion. All of the patients gave informed consent to enter the trial, which was approved by the local ethical committee.

\section{DNA extraction from whole-blood and formalin-fixed paraffin-embedded tissues}

Genomic DNA was extracted from blood samples using an Illustra DNA Extraction Kit BACC2 (GE Healthcare, Buckinghamshire, UK). DNA was also extracted from the formalin-fixed paraffin-embedded thyroid tissues of two women with GD submitted to thyroidectomy by means of a commercial kit (Puregene Core Kit A, Qiagen Sciences).

\section{PCR for SRY sequence}

For the detection of the human Y chromosome, DNA was submitted to two rounds of PCR (35 cycles each) using primers specific for the SRY locus and corresponding to the region upstream of the SRY-coding region. We previously demonstrated that this method has a sensitivity of 1 male cell/1 million female cells (24). Each PCR analysis was 
repeated twice, two negative controls (DNA from two prepubertal girls) and two positive controls (DNA from two men) were included, and special care was taken to avoid external contamination. In particular, all of the samples were handled by a female technician, positive displacement micropipettes were used, and DNA extraction, PCR preparation, and analyses were conducted in separate rooms.

\section{Male DNA quantification}

DNA pools were obtained by mixing the same amount of DNA extracted from ten women with HT, ten women with GD, and ten HC who were previously found to be positive for the presence of FCM by PCR amplification. Each DNA pool was precipitated and concentrated to $1 \mu \mathrm{g} / \mu \mathrm{l}$, and sequential dilutions were conducted from $6600 \mathrm{ng}$ (1 $000000 \mathrm{gEq})$ to $0.0066 \mathrm{ng}$ (1 gEq). Male DNA quantities were expressed in DNA genome equivalents $(\mathrm{gEq})$ by using a conversion factor of $6.6 \mathrm{pg}$ DNA per cell $(1 \mathrm{gEq}=\mathrm{DNA}$ content of a single cell). Dilutions obtained for each pool were subjected to two rounds of PCR. Triplicate analyses were performed for dilutions ranging from 66 to $0.0066 \mathrm{ng}$ in order to improve accuracy and test reliability. Samples were electrophoresed in 3\% agarose gels and visualized and photographed on an u.v. trans-illuminator (VisiDoc-It Imaging System, UVP, Cambridge, UK).

\section{Fluorescence in situ hybridization}

The presence of microchimeric cells was also tested at the tissue level in two GD women who were analyzed for FCM at the peripheral blood level and for whom thyroid tissue was available. In those cases, we performed both the PCR amplification of the SRY gene and the FISH analyses on $4 \mu \mathrm{m}$-thick paraffin-embedded tissue sections, as previously described (25). In particular, the DNA probes used were specific for the $\alpha$-satellite regions of the X (PAC probe pDMX1, locus DXZ1) and Y (band region Yp11.1q11.1, locus DYZ3) chromosomes. The $X$ probe was labeled with digoxigenin and was detected using FITCconjugated antibody anti-digoxigenin (green signal; Roche Diagnostics $\mathrm{GmbH}$ ), whereas the Y probe was labeled with a SpectrumOrange fluorochrome (Vysis, Downers Grove, IL, USA) and was detected as red signal.

Image acquisition was performed on a Leica DMRA2 fluorescence microscope (Leica, Wetzlar, Germany) equipped with Leica filters specific for DAPI, FITC, and Cy3. Images were acquired using a charge-coupled device $(C C D)$ camera (Leica) with a magnification factor of $100 \times$.
Image analysis was performed using Leica CW4000-FISH software version Y1.3.1.

\section{HLA-G polymorphism typing}

In 96/105 AITD cases and in 58/66 controls, the $H L A-G$ $14 \mathrm{bp}$ (14 bp Ins/Del) and the $+3142 \mathrm{C}>\mathrm{G}$ polymorphisms were genotyped by real-time PCR, as previously described $(26,27)$. Briefly, $100 \mathrm{ng}$ of genomic DNA were amplified in a $25 \mu \mathrm{l}$ reaction, and the analysis performed using a 7300 Real-Time PCR System (Applied Biosystems). To analyze the $14 \mathrm{bp}$ polymorphism, the forward primer $5^{\prime}$-GTGATGGGCTGTTTAAAGTGTCACC-3' and the reverse primer $5^{\prime}$-GGAAGGAATGCAGTTCAGCATGA-3' were used. The probe used for detection of the 14-bp deletion allele was 5'-VIC-GAGTGGCAAGTCCCTTTGTGBHQ-3-3', and the probe for the 14-bp insertion allele was 5'-FAM-CAAGATTTGTTCATGCCTTCCC-BHQ-1-3'. To genotype samples for the $+3142 \mathrm{C}>\mathrm{G}$ polymorphism, the forward primer 5'-CCTTTAATTAACCCATCAATCTCTCTTG- $3^{\prime}$ and the reverse primer $5^{\prime}$-TGTCTCCGTCTCTGTCTCAAATTT- $3^{\prime}$ were used. The MGB probe used for the detection of the $3142 \mathrm{C}$ allele was $5^{\prime}$-VIC-TAAGTTATAGCTCAGTGGAC- ${ }^{\prime}$, and the MGB probe for the $3142 \mathrm{G}$ allele was $5^{\prime}$-FAM-TAAGTTATAGCTCAGTGCAC-3'. Each probe had a non-fluorescent quencher at the $3^{\prime}$ end. Amplification was performed with $0.625 \mu$ l Assay Mix $40 \times$ (Applied Biosystems) and $12.5 \mu \mathrm{l}$ PCR master mix $2 \times$. Before the amplification, a pre-read run was performed for $1 \mathrm{~min}$ at $60^{\circ} \mathrm{C}$. The amplification protocol was: an initial step for $10 \mathrm{~min}$ at $95^{\circ} \mathrm{C}$ followed by amplification for $15 \mathrm{~s}$ at $92^{\circ} \mathrm{C}$ and for $60 \mathrm{~s}$ at $60^{\circ} \mathrm{C}$ for 40 cycles. A post-run reading was performed for $1 \mathrm{~min}$ at $60^{\circ} \mathrm{C}$.

\section{Statistical analysis}

Possible differences in the clinical features (age at diagnosis/enrollment, age at the first male child birth, number of sons, and period between the birth of the first male child and diagnosis/enrollment) between GD or HT patients and $\mathrm{HC}$ were assessed by $t$-test and $\chi^{2}$ test, as appropriate. The differences in the prevalence of FCM between women with $\mathrm{GD}, \mathrm{HT}$, or HC and the association of FCM with either clinical features or the $H L A-G$ profile were tested by Fisher or $\chi^{2}$ tests. Odds ratios (ORs) and $95 \% \mathrm{CI}$ were used to assess the strength of the association between the presence/absence of FCM and the presence/absence of the disease. Differences between values were considered significant when $P<0.05$. All of the tests were performed using MedCalc Software version 13.2.2 (B-8400, Ostend, Belgium). 


\section{Results}

Clinical features and blood FCM in patients with GD, patients with $\mathrm{HT}$, and controls

Neither the GD nor the HT group significantly differed from the HC group with respect to age at the first male birth, the period between the birth of the first male child and the diagnosis of AITD, the age at diagnosis or enrollment, and the number of male children (data not shown). The presence of male DNA of presumed fetal origin had a significantly higher prevalence in HC cases than it was in either GD cases ( 63.6 vs $33.3 \%, P=0.0004$, OR 3.5 , 95\% CI $1.723-7.11$ ), HT cases (63.6 vs $27.8 \%$, $P=0.0005$, OR $4.55,95 \%$ CI 1.877-11.03), or AITD women as a whole (63.6 vs $31.4 \%, P<0.0001$, OR $3.818,95 \% \mathrm{CI}$ 1.995-7.308) (Fig. 1A and B). Among either AITD patients or $\mathrm{HC}$, the cases that were positive for the presence of FCM (FMC + ve) were not significantly different from those without FCM (FMC - ve) in terms of age at the birth of first male child, number of male children, interval between the birth of the first male child and diagnosis or enrollment, age at diagnosis or enrollment, and, for patients, the interval between the diagnosis and the enrollment and the association with orbitopathy (Supplementary Table 1, see section on supplementary data given at the end of this article). In GD cases, the type of treatment (anti-thyroid drugs, thyroidectomy, or radiometabolic treatment) and the interval between the thyroidectomy or radioactive iodine ablation and enrollment were also considered, because the ablation of the thyroid tissue could have determined the disappearance of circulating fetal cells, but no differences were noted between FMC + ve and FMC - ve cases (data not shown).

Interestingly, the SRY amplification was successful during the first round PCR in the majority of HCs, but only after a two-round PCR in GD and HT cases, which indicates that there is a higher amount of circulating male DNA in controls than there is in AITD patients. Thus, with the aim of performing a quantitative evaluation, FCM + ve DNA of ten HT patients, ten GD patients, and ten HCs were pooled, and sequential dilutions were done. Interestingly, this quantitative analysis confirmed that male DNA was more abundant in HCs than it was in either GD or HT patients. In particular, in HCs, male DNA could be clearly detected up to a dilution that corresponded to $66 \mathrm{ng}$ total DNA (10000 genome equivalents), whereas it was hardly or not detected at that dilution in GD and HT cases (Fig. 2).
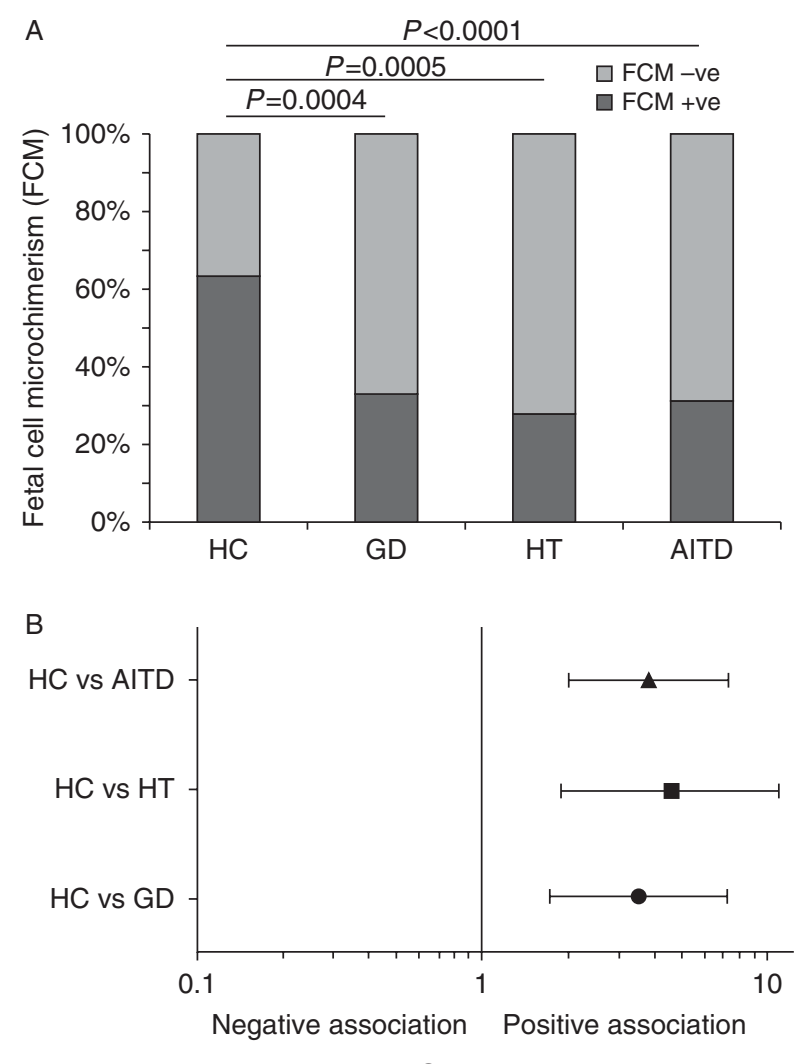

Odds ratio

\section{Figure 1}

(A) The prevalence of fetal cell microchimerism (FCM) in healthy controls (HCs) with respect to Graves' disease (GD), Hashimoto's thyroiditis (HT), or autoimmune thyroid disease (AITD) patients. FCM was significantly more prevalent in HCs than in either GD or HT cases or in AITD women considered as a whole. (B) Forest plot for FCM and AITD risk. The geometric figures and horizontal lines correspond to the odds ratios (ORs) and $95 \% \mathrm{Cls}$ respectively. In all of the cases, OR values indicated that there was a positive association between the presence of FCM and the absence of AITDs, which indicates its protective role in the development of these diseases.

\section{Identification of FCM in the thyroid tissue of women affected with GD}

The thyroid tissue of two GD women, one of whom was positive and one of whom was negative for FCM at the peripheral level, was studied. In both cases, male cells of presumed fetal origin were documented in the tissue by both PCR and FISH analysis. Interestingly, microchimeric cells were detected as forming part of thyroid follicles, interposed between female maternal cells (Fig. 3A, B and C). 


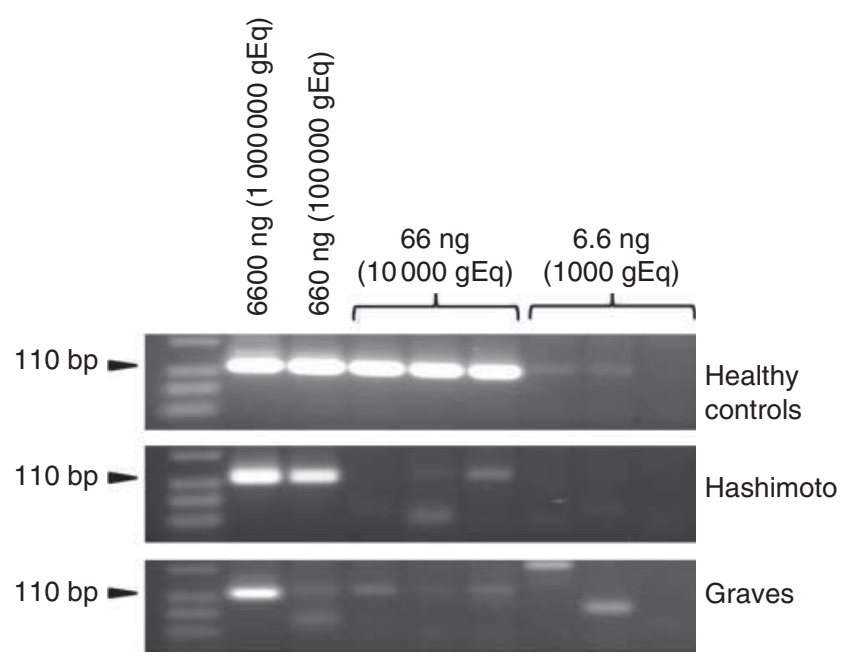

Figure 2

Quantitative evaluation of circulating male DNA in patients with autoimmune thyroid diseases (AITDs) and in healthy controls (HCs). The DNA of ten Hashimoto's thyroiditis (HT) patients, ten Graves' disease (GD) patients, and ten HCs were pooled, and sequential dilutions were obtained. In controls, male DNA could be clearly detected up to a dilution that corresponded to $66 \mathrm{ng}$ total DNA (10 000 genome equivalents), whereas it was hardly or not at all detected at that dilution in GD or HT cases.

Moreover, a microchimeric male cell was identified in a blood vessel (Fig. 3D).

\section{HLA-G genetic polymorphism typing}

The HLA-G genetic polymorphism typing was not different between FCM + ve and - ve patients of the GD, $\mathrm{HT}$, or HC groups or in the AITD cases considered as a whole. In particular, no differences were found in the prevalence of the homozygous genotype (Del/Del) and the Del allele, which correspond to a high secretor profile (Table 1 ). As far as the $+3142 \mathrm{C}>\mathrm{G}$ variant was concerned, no differences were observed between the HT or GD patients and the HCs for both the genotype distribution and the allele frequencies (data not shown).

\section{Discussion}

In the present large series of AITD cases, the prevalence of FCM was found to be significantly higher in HCs than it was in AITD patients, which suggests a protective role for FCM toward the onset of these diseases. Most of the previous studies in systemic and non-systemic autoimmune diseases were done at the peripheral blood level, and contrasting data have been obtained about the possible role of FCM. Some authors considered it to be pathogenic because they found a higher prevalence of FCM in affected women as compared to controls $(5,6,7,8)$ and because of the hypothesis that microchimeric cells might elicit an intra-organ graft vs host rejection (GvHR) $(5,9,28,29)$. Other authors did not confirm these data $(30,31,32,33)$ and did not support the causative role for this phenomenon, which is also observed in nonautoimmune diseases $(17,24,25,34,35,36,37,38,39)$.

The protective role of FCM in AITD that was suggested by the present data is consistent with what has been reported for neoplastic diseases, and in particular for thyroid and breast cancers $(24,25,35,37)$. Based on the immunophenotypic characterization of FMC in neoplastic diseases, we and others hypothesized that fetal cells could migrate from bone marrow niches through blood vessels to reach the injured areas and to differentiate into cells that are able to repair the diseased tissues because at least some of the engrafted fetal cells have stem cell potential $(4,25)$. Moreover, further evidence to support this 'protective' hypothesis has come from several studies in animal models. In particular, the selective homing of fetal cells to the site of organ injury and not to healthy tissues suggests that fetal cells sense specific signals, which enables them
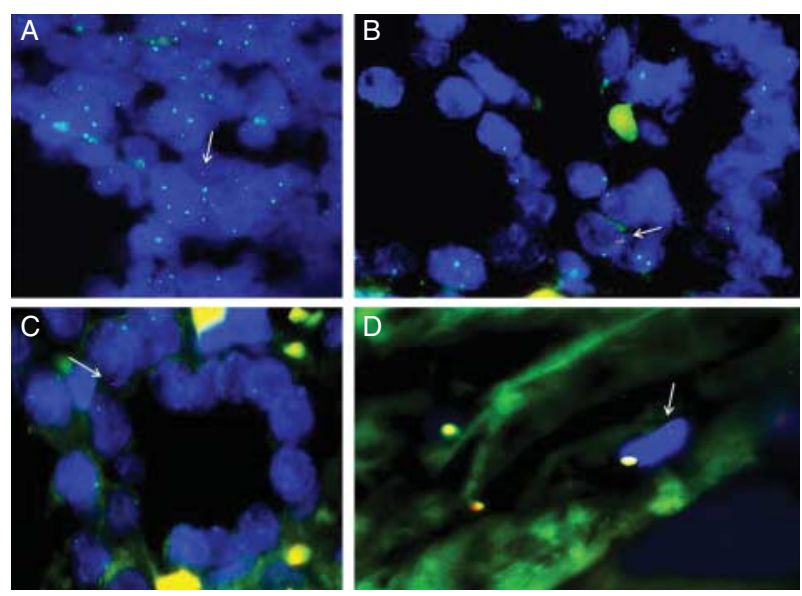

\section{Figure 3}

FISH analysis on two Graves' disease tissues. (A, B and C) Male microchimeric cells (red and green signals, indicated by arrows) were detected interposed between female maternal cells (green signals) to form parts of thyroid follicles. (D) A microchimeric male cell (red and green signal, indicated by an arrow) was identified in a blood vessel. Magnification $100 \times$. 
Table 1 HLA-G genetic polymorphism typing in healthy controls (HC), Hashimoto's thyroiditis (HT) patients, and Graves' disease (GD) patients as either positive or negative for fetal cell microchimerism (FCM).

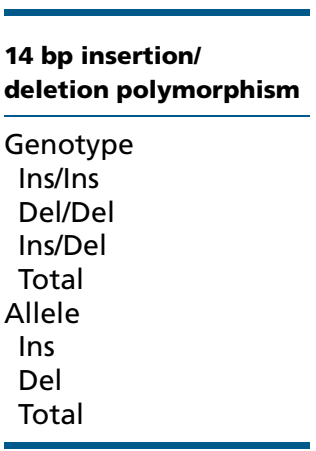

\begin{tabular}{|c|c|c|}
\hline \multicolumn{2}{|c|}{ GD $n(\%)$} & \multirow[b]{2}{*}{$\boldsymbol{P}$} \\
\hline $\mathrm{FCM}$ + ve & FCM - ve & \\
\hline & & 0.41 \\
\hline $4(18.1)$ & $9(23.1)$ & \\
\hline $6(27.3)$ & $10(25.6)$ & \\
\hline $12(54.5)$ & $20(51.3)$ & \\
\hline 22 & 39 & \\
\hline & & 0.57 \\
\hline $20(45.5)$ & $40(51.3)$ & \\
\hline $24(54.5)$ & $38(48.7)$ & \\
\hline 44 & 78 & \\
\hline
\end{tabular}

\begin{tabular}{c} 
HT $n$ \\
\hline FCM +ve \\
\hline $2(20)$ \\
$2(20)$ \\
$6(60)$ \\
10 \\
$10(50)$ \\
$10(50)$ \\
20 \\
\hline
\end{tabular}

+ ve, positive; - ve, negative.

to target diseased tissue $(40,41,42)$. Consistently in the GD cases in the present study, male cells were documented to 'travel' into a blood vessel and were found interposed between female cells and forming follicles in the thyroid. Although we cannot exclude a role for fetal microchimeric cells as being innocent bystanders that do not have any significant biological effect at the thyroid tissue level in GD, two tentative hypotheses can be drawn. First, maleactivated fetal $\mathrm{T}$ cells, monocytes, macrophages, and NK cells could be the effectors of autoimmunity and could be involved in the initiation of autoimmune diseases (alloautoimmunity), but this hypothesis seems to be unlikely because we have not observed male cells within lymphocytic infiltration in the affected thyroid gland. Alternatively, these cells may be recognized as being partially alloimmune, that is, as giving rise to an immune reaction (auto-alloimmunity) in which the effectors are maternal immune cells. Nevertheless, the number of male cells observed in the thyroid glands of these women was too low to support this hypothesis. Second, male microchimeric cells could be involved in the repair/repopulation process because of their follicular localization and their morphology, which resembles that of thyrocytes. Indeed, the presence of male cells interposed between female cells in thyroid follicles, which has already been observed in thyroid cancer (25), in nodular goiter specimens (11), and in the normal thyroids of healthy women (17), seems to reinforce the findings at the blood level and to suggest a protective/repairing role for FCM. Nevertheless, it should be noted that the microchimeric status at the peripheral level may or may not reflect that of the thyroid tissue, as was already observed in thyroid cancer (24). Consistently, Y chromosome cells were found in both of the GD tissues that were analyzed, even though only one of those patients was positive for FCM at the peripheral level. The possibility of extensively studying microchimeric status at the tissue level in AITD is strongly limited by the fact that thyroidectomy is not indicated for the treatment of HT, and it is seldom used for GD patients, who are instead mainly treated with radioiodine.

It should be noted that contradictory data to those presented here were previously obtained by Lepez et al. (18) in a more limited AITD series. Four hypotheses can be drawn to tentatively explain these contrasting results. The first involves the different intervals between diagnosis and enrollment, which was a maximum of 5 years in the Lepez et al. study and ranged from a few months to 30 years in the present study. This longer latency could theoretically explain the differences in the amount of circulating male cells, which could be progressively eliminated over time by the autoimmune process. However, we did not find any correlation between the presence/absence of FCM and the length of the interval between diagnosis and enrollment. The second hypothesis involves the interval between the birth of the youngest son and the age at diagnosis, which was 3-12 months in the Lepez et al. study and 1-60 years in the present study. This also could have contributed to differences in the amount of circulating male cells, which may progressively lessen after delivery. Nevertheless, we did not find any correlation between the presence/absence of FCM and the length of this interval either in previous studies (24) or in the present study. Third, Lepez et al. used FISH analysis, which allowed them to identify intact male cells, whereas our PCR-based method may have also led to the detection of free-DNA released from damaged cells. Still, our qualitative results were also nicely confirmed in the quantitative analysis, which demonstrated a higher amount of male DNA in HCs, and we estimate that our 
analysis was derived mostly from intact cells. Finally, the discordancy could be the result of the low number of patients enrolled by Lepez et al. (11 women) or to the nonselection of control cases. On the contrary, control cases were well selected in the present study by biochemical and ultrasound examinations in order to exclude nonclinically evident thyroid diseases.

In the present study, the $3^{\prime}$ UTR polymorphisms $14 \mathrm{bp}$ insertion/deletion (rs1704) and $+3142 \mathrm{C}>G$ SNP (rs1063320) that control HLA-G expression $(21,22)$ were studied for the first time in AITD. Indeed, because high levels of HLA-G expression seem to be crucial for successful implantation, we hypothesized that a high secretor genetic profile in the mother could be associated with a higher tolerance of fetal cells and is thus associated with higher levels of FMC. No differences in the HLA-G typing or, in particular, in the secretor genetic profile, were found between FCM + ve and - ve cases in the GD, HT or HC groups, which is consistent with data previously obtained in HTs and controls (43). Thus, the present findings allowed us to exclude the suggestion that the higher prevalence of FCM in HCs could be the result of a high secretor genetic profile that leads to a facilitated passage of fetal cells. Along these lines, a recent study tested the same hypothesis by analyzing $H L A-G$ polymorphisms in children from women with scleroderma (44) and showed that a high secretor genetic profile does not allow more fetalto-mother chimerism traffic.

In conclusion, circulating fetal cells are significantly more abundant in HCs than they are in patients with thyroid autoimmunity, which suggests a protective role for FCM in AITDs. The possible contribution to these findings of a high secretor $H L A-G$ genetic profile has been excluded. The localization studies confirmed that microchimeric cells have the ability to migrate to diseased tissues and may have a possible protective/repairing function.

\section{Supplementary data}

This is linked to the online version of the paper at http://dx.doi.org/10.1530/ EJE-15-0028.

\section{Declaration of interest}

The authors declare that there is no conflict of interest that could be perceived as prejudicing the impartiality of the research reported.

\section{Funding}

This research did not receive any specific grant from any funding agency in the public, commercial or not-for-profit sector.

\section{References}

1 Ariga $\mathrm{H}$, Ohto H, Busch MO, Imamura S, Watson R, Reed W \& Lee TH. Kinetics of fetal cellular and cell-free DNA in the maternal circulation during and after pregnancy: implications for noninvasive prenatal diagnosis. Transfusion 200141 1524-1530. (doi:10.1046/j.1537-2995. 2001.41121524.x)

2 Bianchi DW, Zickwolf GK, Weil GJ, Sylvester S \& DeMaria MA. Male fetal progenitor cells persist in maternal blood as long as 27 years postpartum. PNAS 199693 705-708. (doi:10.1073/pnas.93.2.705)

3 O'Donoghue K, Chan J, de la Fuente J, Kennea N, Sandison A, Anderson JR, Roberts IA \& Fisk NM. Microchimerism in female bone marrow and bone decades after fetal mesenchymal stem-cell trafficking in pregnancy. Lancet 2004364 179-182. (doi:10.1016/S0140-6736(04)16631-2)

4 Khosrotehrani K, Johnson KL, Cha DH, Salomon RN \& Bianchi DW. Transfer of fetal cells with multilineage potential to maternal tissue. Journal of the American Medical Association 2004292 75-80. (doi:10.1001/jama.292.1.75)

5 Artlett CM, Smith JB \& Jimenez SA. Identification of fetal DNA and cells in skin lesions from women with systemic sclerosis. New England Journal of Medicine 1998338 1186-1191. (doi:10.1056/NEJM199804233381704)

6 Nelson JL, Furst DE, Maloney S, Gooley T, Evans PC, Smith A, Bean MA, Ober C \& Bianchi DW. Microchimerism and HLA compatible relationships of pregnancy in scleroderma. Lancet 1998351 559-562. (doi:10.1016/S0140-6736(97)08357-8)

7 Johnson KL, McAlindon TE, Mulcahy E \& Bianchi DW. Microchimerism in a female patient with systemic lupus erythematosus. Arthritis and Rheumatism 200144 2107-2111. (doi:10.1002/15290131(200109)44:9<2107::AID-ART361>3.0.CO;2-9)

8 Rak JM, Maestroni L, Balandraud N, Guis S, Boudinet H, Guzian MC, Yan Z, Azzouz D, Auger I, Roudier C et al. Transfer of the shared epitope through microchimerism in women with rheumatoid arthritis. Arthritis and Rheumatism 200960 73-80. (doi:10.1002/art.24224)

9 Klintschar M, Schwaiger P, Mannweiler S, Regauer S \& Kleiber M. Evidence of fetal microchimerism in Hashimoto's thyroiditis. Journal of Clinical Endocrinology and Metabolism 200186 2494-2498. (doi:10.1210/ jcem.86.6.7540)

10 Klintschar M, Immel UD, Kehlen A, Schwaiger P, Mustafa T, Mannweiler S, Regauer S, Kleiber M \& Hoang-Wu C. Fetal microchimerism in Hashimoto's thyroiditis: a quantitative approach. European Journal of Endocrinology/European Federation of Endocrine Societies 2006154 237-241. (doi:10.1530/eje.1.02080)

11 Srivatsa B, Srivatsa S, Johnson KL, Samura O, Lee SL \& Bianchi DW. Microchimerism of presumed fetal origin in thyroid specimens from women: a case-control study. Lancet 2001358 2034-2038. (doi:10.1016/S0140-6736(01)07099-4)

12 Ando T, Imaizumi M, Graves PN, Unger P \& Davies TF. Intrathyroidal fetal microchimerism in Graves' disease. Journal of Clinical Endocrinology and Metabolism 200287 3315-3320. (doi:10.1210/jcem.87.7.8656)

13 Renné C, Ramos Lepez E, Steimle-Grauer SA, Ziolkowski P, Pani MA, Luther C, Holzer K, Encke A, Wahl RA, Bechstein WO et al. Thyroid fetal male microchimerism in mothers with thyroid disorders: presence of $\mathrm{Y}$ chromosomal immunofluorescence in thyroid-infiltrating lymphocytes is more prevalent in Hashimoto's thyroiditis and Graves' disease than in follicular adenomas. Journal of Clinical Endocrinology and Metabolism 200489 5810-5814. (doi:10.1210/jc.2004-1049)

14 Walsh JP, Bremner AP, Bulsara MK, O'Leary P, Leedman PJ, Feddema P $\&$ Michelangeli V. Parity and the risk of autoimmune thyroid disease: a community-based study. Journal of Clinical Endocrinology and Metabolism 200590 5309-5312. (doi:10.1210/jc.2005-0771)

15 Pedersen IB, Laurberg P, Knudsen N, Jorgensen T, Perrild H, Ovesen L \& Rasmussen LB. Lack of association between thyroid autoantibodies and parity in a population study argues against microchimerism as a trigger of thyroid autoimmunity. Journal of Clinical Endocrinology and Metabolism 2006 154 39-45. (doi:10.1530/eje.1.02070) 
16 Sgarbi JA, Kasamatsu TS, Matsumura LK \& Maciel RM. Parity is not related to autoimmune thyroid disease in a population-based study of Japanese-Brazilians. Thyroid 201020 1151-1156. (doi:10.1089/thy. 2009.0424)

17 Koopmans M, Kremer Hovinga IC, Baelde HJ, Harvey MS, de Heer E, Bruijn JA \& Bajema IM. Chimerism occurs in thyroid, lung, skin and lymph nodes of women with sons. Journal of Reproductive Immunology 200878 68-75. (doi:10.1016/j.jri.2008.01.002)

18 Lepez T, Vandewoestyne M, Hussain S, Van Nieuwerburgh F, Poppe K, Velkeniers B, Kaufman JM \& Deforce D. Fetal microchimeric cells in blood of women with an autoimmune thyroid disease. PLoS ONE 2011 6 e29646. (doi:10.1371/journal.pone.0029646)

19 Rizzo R, Vercammen M, van de Velde H, Horn PA \& Rebmann V. The importance of HLA-G expression in embryos, trophoblast cells, and embryonic stem cells. Cellular and Molecular Life Sciences 201168 341-352. (doi:10.1007/s00018-010-0578-1)

20 Le Bouteiller P \& Mallet V. HLA-G and pregnancy. Reviews of Reproduction 19972 7-13. (doi:10.1530/ror.0.0020007)

21 Hviid TV, Hylenius S, Rørbye C \& Nielsen LG. HLA-G allelic variants are associated with differences in the HLA-G mRNA isoform profile and HLA-G mRNA levels. Immunogenetics 200355 63-79. (doi:10.1007/ s00251-003-0547-z)

22 Rizzo R, Bortolotti D, Fredj NB, Rotola A, Cura F, Castellazzi M, Tamborino C, Seraceni S, Baldi E, Melchiorri L et al. Role of HLA-G 14bp deletion/insertion and $+3142 \mathrm{C}>\mathrm{G}$ polymorphisms in the production of sHLA-G molecules in relapsing-remitting multiple sclerosis. Human Immunology 201273 1140-1146. (doi:10.1016/j.humimm.2012.08.005)

23 Rizzo R, Andersen AS, Lassen MR, Sørensen HC, Bergholt T, Larsen MH, Melchiorri L, Stignani M, Baricordi OR \& Hviid TV. Soluble human leukocyte antigen-G isoforms in maternal plasma in early and late pregnancy. American Journal of Reproductive Immunology 200962 320-338. (doi:10.1111/j.1600-0897.2009.00742.x)

24 Cirello V, Perrino M, Colombo C, Muzza M, Filopanti M, Vicentini L, Beck-peccoz P \& Fugazzola L. Fetal cell microchimerism in papillary thyroid cancer: studies in peripheral blood and tissues. International Journal of Cancer 2010126 2874-2878. (doi:10.1002/ijc.24993)

25 Cirello V, Recalcati MP, Muzza M, Rossi S, Perrino M, Vicentini L, BeckPeccoz P, Finelli P \& Fugazzola L. Fetal cell microchimerism in papillary thyroid cancer: a possible role in tumor damage and tissue. Cancer Research 200868 8482-8488. (doi:10.1158/0008-5472.CAN-08-0672)

26 Djurisic S, Sørensen AE \& Hviid TV. A fast and easy real-time PCR genotyping method for the HLA-G 14-bp insertion/deletion polymorphism in the $3^{\prime}$ untranslated region. Tissue Antigens 201279 186-189. (doi:10.1111/j.1399-0039.2011.01830.x)

27 Bortolotti D, Gentili V, Melchiorri L, Rotola A \& Rizzo R. An accurate and reliable real time SNP genotyping assay for the HLA-G +3142bp $\mathrm{C}>\mathrm{G}$ polymorphism. Tissue Antigens 201280 259-262. (doi:10.1111/ j.1399-0039.2012.01926.x)

28 Nelson JL. Maternal-fetal immunology and autoimmune disease: is some autoimmune disease auto-alloimmune or allo-autoimmune? Arthritis and Rheumatism 199639 191-194. (doi:10.1002/art. 1780390203)

29 Ando T \& Davies TF. Postpartum autoimmune thyroid disease: the potential role of fetal microchimerism. Journal of Clinical Endocrinology and Metabolism 200388 2965-2971. (doi:10.1210/jc.2002-021903)

30 Murata H, Nakauchi H \& Sumida T. Microchimerism in Japanese women patients with systemic sclerosis. Lancet $19993 \mathbf{3 5 4} 220$. (doi:10.1016/S0140-6736(99)00164-6)
31 Gannagé M, Amoura Z, Lantz O, Piette JC \& Caillat-Zucman S Feto-maternal microchimerism in connective tissue diseases. European Journal of Immunology 200232 3405-3413. (doi:10.1002/15214141(200212))

32 Invernizzi P, De Andreis C, Sirchia SM, Battezzati PM, Zuin M, Rossella F, Perego F, Bignotto M, Simoni G \& Podda M. Blood fetal microchimerism in primary biliary cirrhosis. Clinical and Experimental Immunology 2000 122 418-422. (doi:10.1046/j.1365-2249.2000.01381.x)

33 Yan Z, Lambert NC, Guthrie KA, Porter AJ, Loubiere LS, Madeleine MM, Stevens AM, Hermes HM \& Nelson JL. Male microchimerism in women without sons: quantitative assessment and correlation with pregnancy history. American Journal of Medicine 2005118 899-906. (doi:10.1016/ j.amjmed.2005.03.037)

34 Gadi VK, Malone KE, Guthrie KA, Porter PL \& Nelson JL. Case-control study of fetal microchimerism and breast cancer. PLOS ONE 20083 e1706. (doi:10.1371/journal.pone.0001706)

35 Gilmore GL, Haq B, Shadduck RK, Jasthy SL \& Lister J. Fetal-maternal microchimerism in normal parous females and parous female cancer patients. Experimental Hematology 200836 1073-1077. (doi:10.1016/ j.exphem.2008.03.020)

36 Dubernard G, Oster M, Chareyre F, Antoine M, Rouzier R, Uzan S, Aractingi S \& Khosrotehrani K. Increased fetal cell microchimerism in high grade breast carcinomas occurring during pregnancy. International Journal of Cancer 2009124 1054-1059. (doi:10.1002/ijc.24036)

37 O'Donoghue K, Sultan HA, Al-Allaf FA, Anderson JR, Wyatt-Ashmead J $\&$ Fisk NM. Microchimeric fetal cells cluster at sites of tissue injury in lung decades after pregnancy. Reproductive Biomedicine Online 200816 382-390. (doi:10.1016/S1472-6483(10)60600-1)

38 Cha D, Khosrotehrani K, Kim Y, Stroh H, Bianchi DW \& Johnson KL. Cervical cancer and microchimerism. Obstetrics and Gynecology 2003 102 774-781. (doi:10.1016/S0029-7844(03)00615-X)

39 Nguyen Huu S, Oster M, Avril MF, Boitier F, Mortier L, Richard MA, Kerob D, Maubec E, Souteyrand P, Moguelet P et al. Fetal microchimeric cells participate in tumour angiogenesis in melanomas occurring during pregnancy. American Journal of Pathology 2009174 630-637. (doi:10.2353/ajpath.2009.080566)

40 Pritchard S, Hoffman AM, Johnson KL \& Bianchi DW. Pregnancyassociated progenitor cells: an under-recognized potential source of stem cells in maternal lung. Placenta 201132 S298-S303. (doi:10.1016/ j.placenta.2011.04.007)

41 Kara RJ, Bolli P, Karakikes I, Matsunaga I, Tripodi J, Tanweer O, Altman P, Shachter NS, Nakano A, Najfeld V et al. Fetal cells traffic to injured maternal myocardium and undergo cardiac differentiation. Circulation Research 2012110 82-93. (doi:10.1161/CIRCRESAHA.111.249037)

42 Seppanen E, Roy E, Ellis R, Bou-Gharios G, Fisk NM \& Khosrotehrani K. Distant mesenchymal progenitors contribute to skin wound healing and produce collagen: evidence from a murine fetal microchimerism model. PLoS ONE 20138 e62662. (doi:10.1371/journal.pone.0062662)

43 Dardano A, Rizzo R, Polini A, Stignani M, Tognini S, Pasqualetti G, Ursino S, Colato C, Ferdeghini M, Baricordi OR et al. Soluble human leukocyte antigen-G and its insertion/deletion polymorphism in papillary thyroid carcinoma: novel potential biomarkers of disease? Journal of Clinical Endocrinology and Metabolism 201297 4080-4086. (doi:10.1210/jc.2012-2231)

44 Picard C, Di Cristofaro J, Azzouz DF, Kanaan SB, Roudier J \& Lambert NC. Analyzing HLA-G polymorphisms in children from women with scleroderma. Human Immunology $2013 \mathbf{7 4}$ 468-472. (doi:10.1016/j.humimm.2012.11.030)

Received 8 January 2015

Revised version received 26 March 2015

Accepted 27 April 2015 